\title{
Pulmonary stenosis and pulmonary regurgitation: both ends of the spectrum in residual hemodyna- mic impairment after tetralogy of Fallot repair
}

\author{
Byung Won Yoo, MD', Han Ki Park, MD, PhD² \\ ${ }^{1}$ Department of Clinical Pharmacology, Clinical Trial Center, Severance Hospital, Yonsei University College of Medicine, Seoul, ${ }^{2}$ Department of Cardiovascular Surgery, \\ Yonsei University College of Medicine, Seoul, Korea
}

Repair of tetralogy of Fallot (TOF) has shown excellent outcomes. However it leaves varying degrees of residual hemodynamic impairment, with severe pulmonary stenosis (PS) and free pulmonary regurgitation (PR) at both ends of the spectrum. Since the 1980s, studies evaluating late outcomes after TOF repair revealed the adverse impacts of residual chronic PR on RV volume and function; thus, a turnaround of operational strategies has occurred from aggressive RV outflow tract (RVOT) reconstruction for complete relief of RVOT obstruction to conservative RVOT reconstruction for limiting PR. This transformation has raised the question of how much residual PS after conservative RVOT reconstruction is acceptable. Besides, as pulmonary valve replacement (PVR) increases in patients with RV deterioration from residual PR, there is concern regarding when it should be performed. Regarding residual PS, several studies revealed that PS in addition to PR was associated with less PR and a small RV volume. This suggests that PS combined with PR makes RV diastolic property to protect against dilatation through RV hypertrophy and supports conservative RVOT enlargement despite residual PS. Also, several studies have revealed the pre-PVR threshold of RV parameters for the normalization of RV volume and function after PVR, and based on these results, the indications for PVR have been revised. Although there is no established strategy, better understanding of RV mechanics, development of new surgical and interventional techniques, and evidence for the effect of PVR on RV reverse remodeling and its late outcome will aid us to optimize the management of TOF.

Key words: Pulmonary stenosis, Pulmonary regurgitation, Tetralogy of Fallot, Heart failure

\section{Introduction}

Tetralogy of Fallot (TOF) is the most common form of cyanotic congenital heart disease and has been successfully repaired since the first intracardiac repair in 1954 ${ }^{11}$. However, although the repair of TOF has showed excellent outcomes (i.e., a 20-year survival rate of approximately 90\%), it leaves varying degrees of residual hemodynamic impairment. Varying degrees of pulmonary regurgitation (PR) and/or pulmonary stenosis (PS) remain in the majority of patients after right ventricular outflow tract (RVOT) reconstruction, and severe PS and free PR are at both ends of the spectrum in residual hemodynamic impairment.

In the early period, the preferred surgical techniques were aggressive RVOT enlargement using a transannular patch, pulmonary velvectomy, and large right ventriculotomy for the complete relief of RVOT obstruction despite resultant severe PR because PR was thought to be a benign lesion. However, since the 1980s, late outcome studies revealed
Corresponding author: Byung Won Yoo, MD Department of Clinical Pharmacology, Clinical Trial Center, Severance Hospital, Yonsei University College of Medicine, 50 Yonsei-ro, Seodaemun-gu, Seoul 120-752, Korea

Tel: +82-2-2228-0465

Fax: +82-2-392-0668

E-mail: bwyoo@yuhs.ac

Received: 26 December 2012 Accepted: 14 April 2013
Copyright (C) 2013 by The Korean Pediatric Society

This is an open-access article distributed under the terms of the Creative Commons Attribution NonCommercial License (http://creativecommons.org/ licenses/by-nc/3.0/) which permits unrestricted noncommercial use, distribution, and reproduction in any medium, provided the original work is properly cited. 
that chronic PR can lead to right ventricular (RV) volume overload and dysfunction, resulting in an increase in long-term morbidity and mortality ${ }^{2-4)}$. A remarkable turnaround of the technique used in TOF repair has occurred, thus currently most centers employ surgical strategies that preserve the pulmonary annulus and valve in order to limit PR. Thereafter, the residual PS that results from conservative RVOT enlargement and valvesparing techniques is confronted and the acceptable amount of residual PS is concerned. On the other hand, as pulmonary valve replacement (PVR) is increasing in patients with RV deterioration from residual PR after TOF repair, there is concern regarding when PVR should be performed. This article reviews the main issues for residual PR and PS after the repair of TOF in order to optimize the surgical strategies in these patients.

\section{PR: what are the major determinants and risk factors?}

During the last 2 decades, it has been well recognized that patients with repaired TOF are at risk for exercise intolerance, right heart failure, life-threatening ventricular arrhythmia, and sudden death at late follow-up owing to residual chronic $\mathrm{PR}^{5-}$
9). Numerous studies have shown a close relationship between the degree of PR and RV dimensions and between the RV dimensions and RV ejection fraction (EF) (Fig. 1) ${ }^{10-13)}$, although the degree of PR has no direct relationship with the RV EF. In addition, left ventricular (LV) function deteriorates with progressive RV dysfunction through interventricular interaction, the so-called "reversed Bernheim effect" (Fig. 2) (5). $^{\text {,10 }}$

Considering the major determinants of PR, the hemodynamic mechanics of PR are somewhat different from those of aortic regurgitation (AR). The major determinants of semilunar valve regurgitation are the size of the regurgitant orifice, the diastolic pressure gradient between the great artery and ventricle, the ventricular diastolic compliance, and the duration of diastole ${ }^{14)}$. While the diastolic pressure gradient between the aorta and $\mathrm{LV}$ is an overwhelming determinant in AR, all the variables may work together in determining the degree of PR without a dominant factor. Because of the low pressure and low impedance in the pulmonary vasculature, other factors play a relatively important role. Under this circumstance, we can understand the pathophysiology and time course of chronic PR (Fig. 3$)^{15}$. Low compliance of a hypertrophied RV early after TOF repair and the relatively high heart rate in young age (short
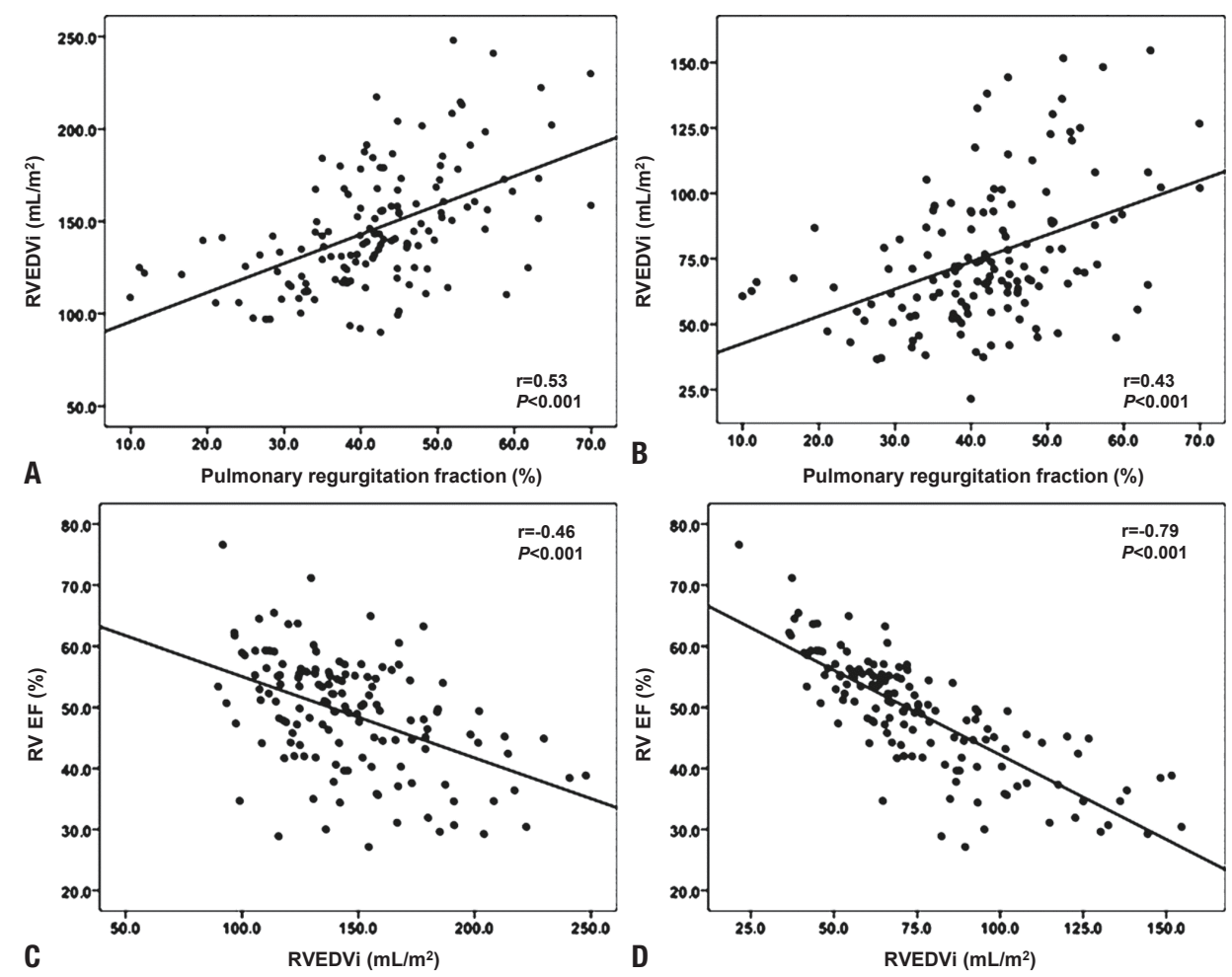

Fig. 1. Right ventricular (RV) mechanics after repair of tetralogy of Fallot. (A, B) Correlations between the pulmonary regurgitation fraction and RV volume. (C, D) Correlations between the RV volume and function. RVEDVi, right ventricular end-diastolic volume index; RVESVi, right ventricular end-systolic volume index; RV EF, right ventricular ejection fraction. Adapted from Yoo et al. J Thorac Cardiovasc Surg 2012;143:1299$304^{10)}$. 

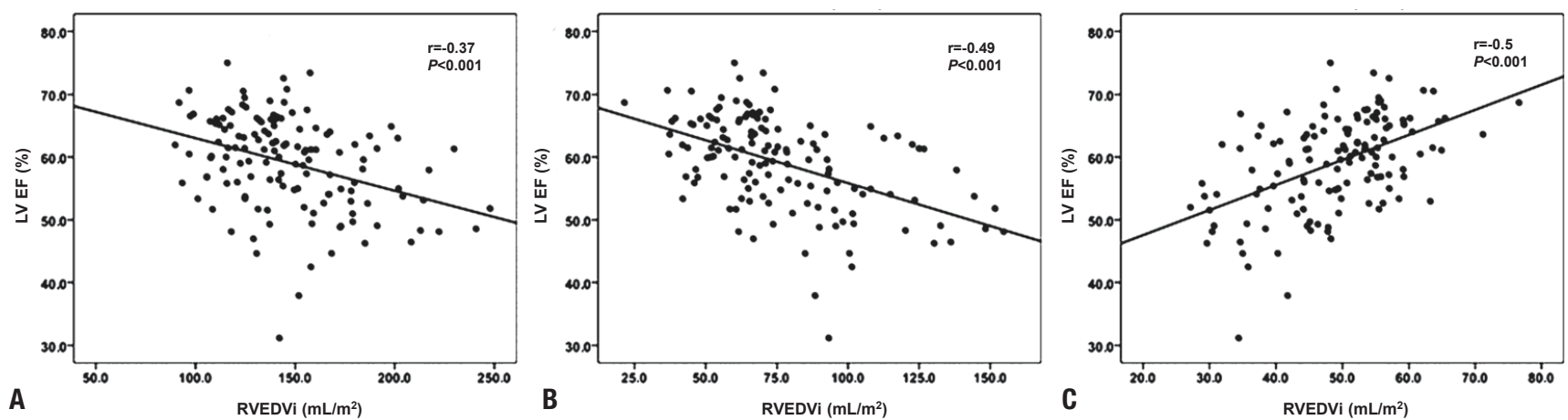

Fig. 2. Right ventricular-left ventricular (RV-LV) interaction after repair of tetralogy of Fallot. (A, B) Correlations between RV volume and LV EF. (C) Correlation between RV and LV EF. RVEDVi, right ventricular end-diastolic volume index; RVESVi, right ventricular end-systolic volume index; LV EF, left ventricular ejection fraction; RV EF, right ventricular ejection fraction. Adapted from Yoo et al. J Thorac Cardiovasc Surg 2012;143:1299-304 ${ }^{10}$.

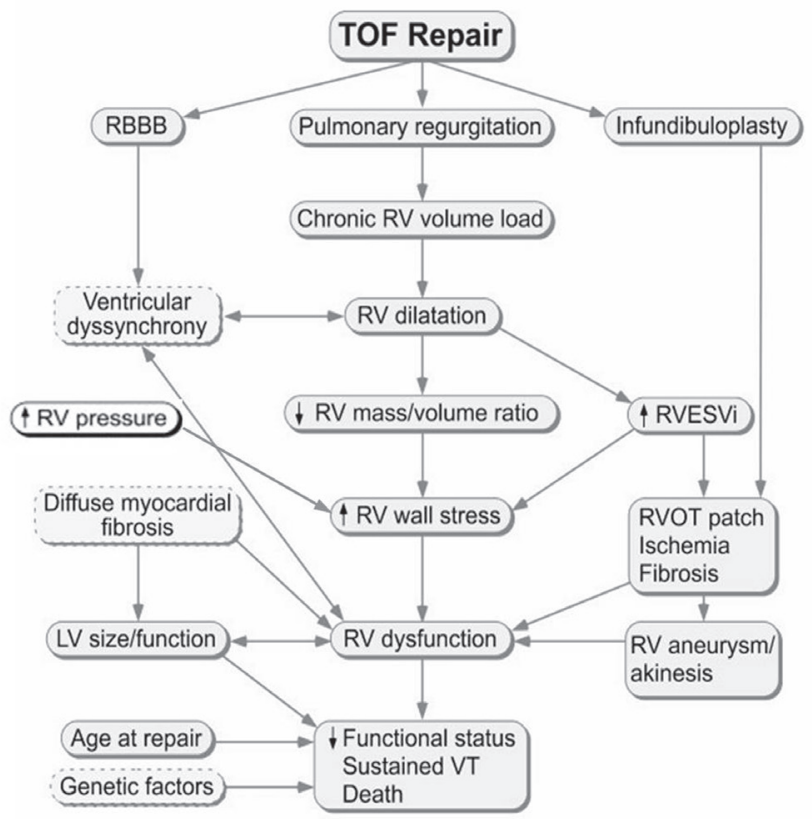

Fig. 3. The pathophysiology and influencing factors on right ventricular (RV) deterioration from chronic pulmonary regurgitation (PR) after repair of tetralogy of Fallot (TOF) ${ }^{15}$. RBBB, right bundle branch block; RVEDVi, right ventricular end-diastolic volume index; RVOT, right ventricular outflow tract; VT, ventricular tachycardia.

duration of diastole) may limit PR despite the large regurgitant orifice, and changes in these factors at late follow-up may augment PR in long-term survivors. Over a long period after the elimination of RVOT obstruction, decreases of RV mass and RV dilatation by PR develop and cause a decrease in the mass/ volume ratio of RV, an increase in RV wall stress, and finally RV dysfunction. Thus, generally, patients with repaired TOF tolerate chronic PR for decades, and the development of symptoms and mortality exponentially increase after the third postoperative decade $^{16,17)}$.

However, deterioration of the RV caused by PR is not consistent in patients with repaired TOF. Some patients have shown severely progressive RV dilatation and dysfunction with time, while other patients have tolerated PR well, resulting in preserved RV volume and function. What accounts for this difference in patients after TOF repair? Many previous studies have tried to find out the risk factors for RV deterioration caused by PR. However, it is not always easy to demonstrate the clear impact of related factors on RV mechanics because of confounding factors from anatomic diversity, advances in surgery and treatment, residual or acquired hemodynamic impairment after repair, and combined arrhythmia. Nonetheless, some studies have revealed that palliative shunt operation, age at the time of the repair, the use of a transannular patch, and aneurysmal dilatation of RVOT have adverse effects on RV volume and function ${ }^{4,5,18-21)}$. These results led us to develop several modified techniques of conservative RVOT enlargement and valve sparing in order to avoid using a transannular patch and developing aneurismal dilatation of the $\mathrm{RVOT}^{22,23)}$, although the late outcome of these techniques is not yet demonstrated. However, debates for other factors have not been conclusive. A recent study revealed that previous palliative shunt history was not a risk factor for PVR ${ }^{24)}$. Regarding age at the time of the repair, some reports suggested that early repair (i.e., $<6$ months of age) may not be beneficial because of a more common transannular patch and lesser restrictive physiology repair ${ }^{25)}$, and others suggested that repair after 1 year of age was correlated with a lower quality of life $\mathrm{f}^{5,26)}$.

Restrictive RV physiology (i.e., the condition of decreased RV diastolic compliance) has been recognized to limit the adverse effects of PR, resulting in a smaller RV size, improved exercise performance, and a lowered propensity to arrhythmia ${ }^{8,27,28)}$. However, some cardiac magnetic resonance (CMR) imaging studies have disagreed with the beneficial effect of restrictive physiology ${ }^{12,29,30)}$. Although the reason of this discrepancy is not clear, it is suggested that the difference in defining restrictive physiology between CMR imaging and Doppler echocardiography may have caused the inconsistent results ${ }^{31)}$. 
CMR measures the average antegrade diastolic flow through many respiratory cycles, while Doppler echocardiography demonstrates the presence of that flow throughout all the respiratory cycles. Future studies comparing the differences between both methods are needed in order to determine the impact of restrictive RV physiology.

Although controversy regarding the risk factors and pathophysiology of chronic PR still exists, a better understanding of the RV mechanics after repair of TOF will help us to optimize management strategies.

\section{PR: how much PR is tolerable and for how long is PR tolerable?}

Similar to the natural course of severe AR, it is considered that irreversible myocardial damage may develop in the right ventricle after a period of reversible dysfunction. On the other hand, early PVR to prevent irreversible RV deterioration frequently requires reintervention due to failure of the implanted valve. Regarding morbidity and mortality, studies have shown that exercise performance might improve after PVR, but it is not affected with the degree of pre-PVR ventricular remodeling ${ }^{32-34)}$. Another study showed that PVR for symptomatic RV dilation did not reduce the incidence of ventricular tachycardia or death $^{35)}$. These results raise the following question: when should PVR be performed?

Although there are no definitive data to make a decision, several studies have revealed the pre-PVR threshold of RV parameters for the normalization of RV volume and function after PVR. The values of threshold showed some difference in individual studies; however, it is known that RV deterioration

Table 1. Indications for pulmonary valve replacement (PVR) in patients with repaired tetralogy of Fallot (TOF) or similar physiology with moderate or severe pulmonary regurgitation (regurgitation fraction $\geq 25 \%)^{15}$ )

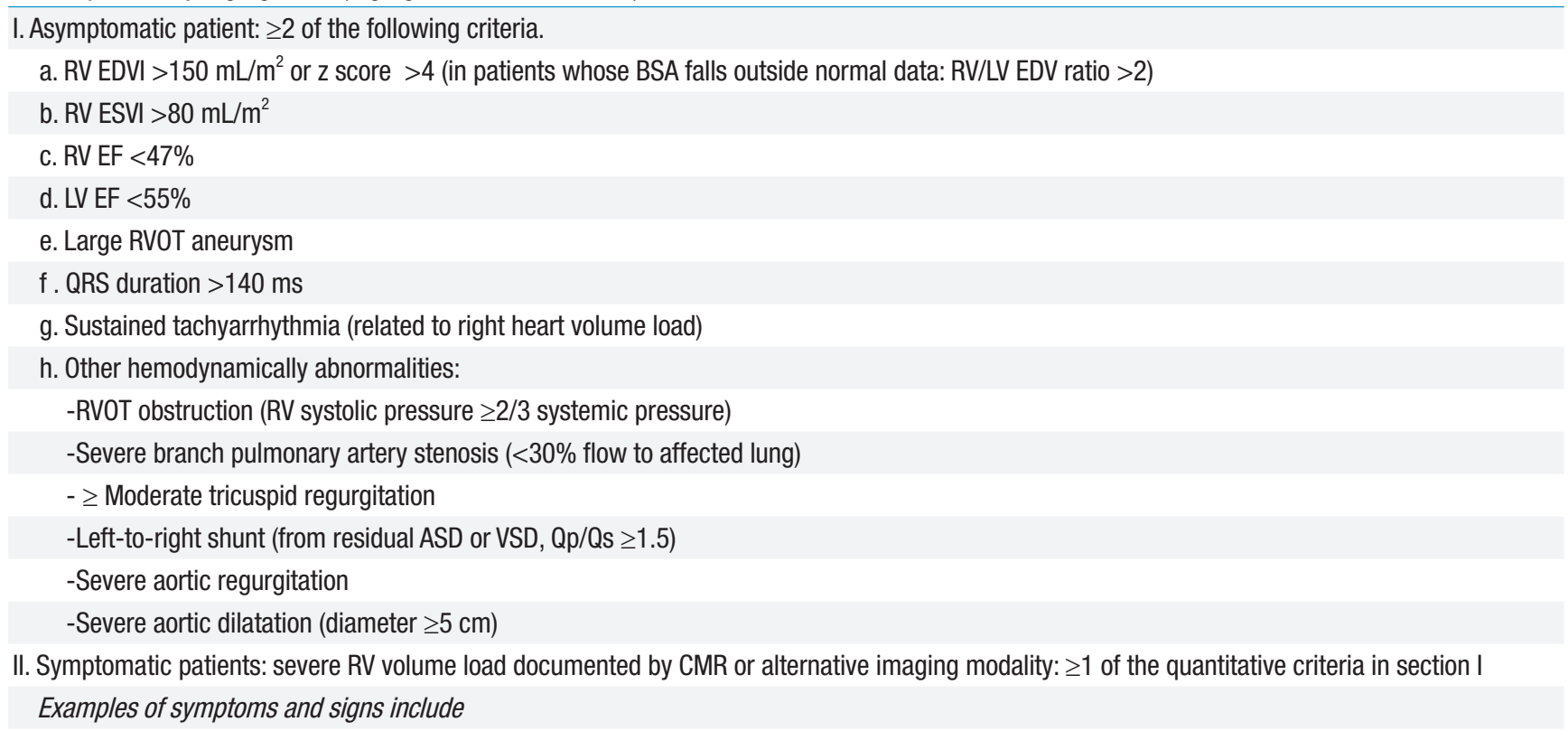

a. Exercise intolerance documented by exercise testing with metabolic cart ( $\leq 70 \%$ predicted peak $\mathrm{VO}_{2}$ for age and gender, not explained by chronotropic incompetence)

b. Signs and symptoms of heart failure

c. Syncope attributable to arrhythmia

III. Special considerations: higher risk of adverse clinical outcomes.

a. TOF repair at age $\geq 3 \mathrm{yr}: \geq 1$ of the quantitative criteria in section I

b. Pregnant women with severe PR and RV dilatation and/or dysfunction: may be considered if fulfilling $\geq 1$ of the quantitative criteria in section I (no evidence is available to support benefit from prepregnancy PVR)

$\mathrm{RV}$, right ventricular; EDVI, end-diastolic volume index; BSA, body surface area; EDV, end-diastolic volume; LV, left ventricular; ESVI, end-systolic volume index; EF, ejection fraction; RVOT, right ventricular outflow tract; ASD, atrial septal defect; VSD, ventricular septal defect; Qp/Qs, pulmonary-to-systemic flow ratio; CMR, cardiac magnetic resonance; PR, pulmonary regurgitation. 
beyond a certain threshold cannot be recovered after PVR. The threshold values identified in each study are as follows: Therrien et al. ${ }^{36}$, $\mathrm{RV}$ end-diastolic volume index (RVEDVi) $\leq 170$ $\mathrm{mL} / \mathrm{m}^{2}$; Oosterhof et al. ${ }^{37)}$, RVEDVi $<160 \mathrm{~mL} / \mathrm{m}^{2}$ and RV endsystolic volume index (RVESVi) $<82 \mathrm{~mL} / \mathrm{m}^{2}$; Buechel et al. ${ }^{38}$ ), RVEDVi $<150 \mathrm{~mL} / \mathrm{m}^{2}$; Frigiola et al. ${ }^{34)}, \mathrm{RV} / \mathrm{LV}$ ratio $>2$; Lee et al. ${ }^{39)}$, RVEDVi $\leq 163 \mathrm{~mL} / \mathrm{m}^{2}$ and RVESVi $\leq 80 \mathrm{~mL} / \mathrm{m}^{2}$; and Geva et al. ${ }^{40)}$, RVEDVi $<150 \mathrm{~mL} / \mathrm{m}^{2}$ and RVESVi $<90 \mathrm{~mL} / \mathrm{m}^{2}$. Similarly, our hospital data presented at the World Congress of Pediatric Cardiology and Cardiac Surgery (Cairns, Australia) in 2009 showed that patients with severe RV deterioration (i.e., RVEDVi $\geq 180 \mathrm{~mL} / \mathrm{m}^{2}$, RVESVi $\geq 90 \mathrm{~mL} / \mathrm{m}^{2}, \mathrm{RV}$ EF $\leq 40 \%$, and QRS duration $\geq 170 \mathrm{~ms}$ ) could not fully recover their RV volume to a normal value (RVEDVi $\leq 110 \mathrm{~mL} / \mathrm{m}^{2}$ and RVESVi $\leq 55 \mathrm{~mL} /$ $\mathrm{m}^{2}$ ) after PVR.

Based on the results to date, Geva ${ }^{15)}$ recently recommended indications for PVR (Table 1). As shown in this recommendation, PVR in symptomatic patients is generally accepted; however, the indication for asymptomatic patients, which is the major concern, has not been clearly established. In addition, the late outcome of PVR after TOF repair is necessary for us to balance this indication between the benefits of the elimination of RV volume load and the disadvantages of frequent reinterventions.

\section{PS: does it only have detrimental effect on RV mechanics after TOF repair?}

Because a previous study showed that residual RVOT obstruction was related with early postoperative mortality ${ }^{41}$, there was no doubt that PS must be completely removed during total repair of TOF. During the last 2 decades, while it was revealed that PR has been related to the most severe adverse outcomes at late follow-up, residual branch pulmonary artery stenosis has been recognized to have an adverse effect on RV deterioration caused by PR based on a report showing that transient balloon occlusion of the unilateral branch pulmonary artery increased $\mathrm{PR}^{42)}$.

However, when we attempt the various modified techniques of RVOT enlargement in order to limit PR, we are faced with the distress that it is not possible to eliminate both PS and PR using an ideal technique. Even, a technique that gets rid of all PS and PR is referred to the 'Holy Grail'. However, we found some results that were reassuring. In an animal study, PR combined with PS was associated with enhanced RV myocardial contractility and decreased RV diastolic compliance ${ }^{43}$ in marked contrast to the data in an isolated PR model ${ }^{44)}$. Additionally, in our clinical experience, patients with PS in addition to PR (PS+PR) have been able to tolerate chronic PR better than those with isolated PR. This finding was demonstrated in our recent study ${ }^{10)}$. In our study, the pressure gradient of PS in the PS+PR group was closely correlated with a smaller PR fraction and smaller RV volume indexes even though there was no difference in the PR fraction, the transannular patch ratio, or the frequency of restrictive physiology between the PS+PR group and the isolated PR group (Fig. 4) ${ }^{10)}$. In multivariate analysis, the pressure gradient of PS and PR fraction were revealed as definite predictors of RV volume and function in these patients. Furthermore, a recent report on percutaneous pulmonary valve implantation (PPVI) in patients with PS and/or PR revealed that both ventricular responses to exercise in the PS and/or PR group showed superior improvement after PPVI, while those in the isolated PR group did not improve at all ${ }^{45}$.

Based on the results of the previously mentioned animal model $^{43)}$ and our study, it is suggested that PS in addition to PR makes RV diastolic property to protect against RV dilatation through the RV hypertrophy. These results support the fact that RV diastolic compliance has an important role in limiting RV dilatation from PR and indicate why we should choose conservative RVOT enlargement strategies despite residual PS. Although the question of how much PS is acceptable remains unanswered, we know that a proper relief of RVOT obstruction
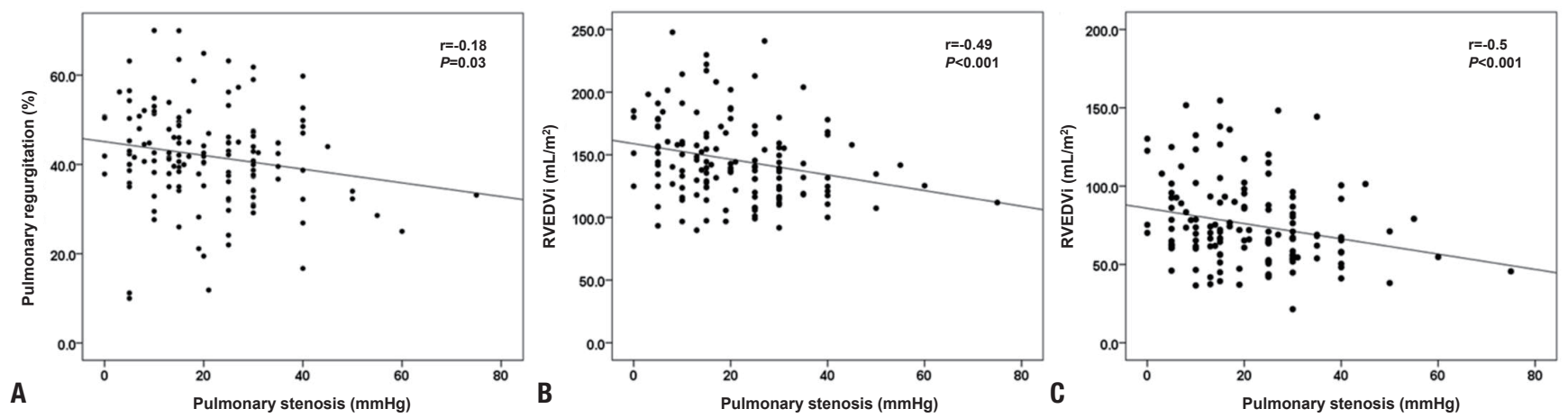

Fig. 4. The impact of pressure load on right ventricular (RV) volume and function. Correlations between the peak pressure gradient of pulmonary stenosis and (A) pulmonary regurgitation fraction (\%), (B) RV end-diastolic volume indexes (RVEDVi), (C) RV end-systolic volume indexes (RVESVi). Adapted from Yoo et al. J Thorac Cardiovasc Surg 2012;143:1299-304 ${ }^{10}$. 
with acceptable residual stenosis is more advantageous than aggressive RVOT enlargement in the long-term outcome of patients with repaired TOF.

\section{Conclusions}

The repair of TOF, which we believed is the most successful story in surgery for congenital heart disease, faced a remarkable turning point, because the complex pathophysiology of residual PS and PR made us regard PR as a benign consequence. Based on the studies to date, the conservative RVOT enlargement and valve-sparing technique, even at the expense of residual PS, is reasonable to prevent RV deterioration from chronic PR in late follow-up.

If studies on patients with repaired TOF continue, better understanding of RV mechanics after TOF repair, development of new surgical and interventional techniques, and evidence for the effect of PVR on RV reverse remodeling and its late outcome will aid us to optimize the management of TOF.

\section{Conflict of interest}

No potential conflict of interest relevant to this article was reported.

\section{References}

1. Lillehei CW, Cohen M, Warden HE, Read RC, Aust JB, Dewall RA, et al. Direct vision intracardiac surgical correction of the tetralogy of Fallot, pentalogy of Fallot, and pulmonary atresia defects; report of first ten cases. Ann Surg 1955;142:418-42.

2. Wessel HU, Cunningham WJ, Paul MH, Bastanier CK, Muster AJ, Idriss FS. Exercise performance in tetralogy of Fallot after intracardiac repair. J Thorac Cardiovasc Surg 1980;80:582-93.

3. Carvalho JS, Shinebourne EA, Busst C, Rigby ML, Redington AN. Exercise capacity after complete repair of tetralogy of Fallot: deleterious effects of residual pulmonary regurgitation. Br Heart J 1992;67:470-3.

4. Gatzoulis MA, Balaji S, Webber SA, Siu SC, Hokanson JS, Poile C, et al. Risk factors for arrhythmia and sudden cardiac death late after repair of tetralogy of Fallot: a multicentre study. Lancet 2000;356:975-81.

5. Geva T, Sandweiss BM, Gauvreau K, Lock JE, Powell AJ. Factors associated with impaired clinical status in long-term survivors of tetralogy of Fallot repair evaluated by magnetic resonance imaging. J Am Coll Cardiol 2004;43:1068-74.

6. Owen AR, Gatzoulis MA. Tetralogy of Fallot: Late outcome after repair and surgical implications. Semin Thorac Cardiovasc Surg Pediatr Card Surg Annu 2000;3:216-26.

7. Khairy P, Landzberg MJ, Gatzoulis MA, Lucron H, Lambert J, Marcon F, et al. Value of programmed ventricular stimulation after tetralogy of fallot repair: a multicenter study. Circulation
2004;109:1994-2000.

8. Gatzoulis MA, Till JA, Somerville J, Redington AN. Mechanoelectrical interaction in tetralogy of Fallot. QRS prolongation relates to right ventricular size and predicts malignant ventricular arrhythmias and sudden death. Circulation 1995;92:231-7.

9. Redington AN. Determinants of short- and long-term outcome in the surgical correction of tetralogy of Fallot. Curr Opin Pediatr 1993;5:619-22.

10. Yoo BW, Kim J0, Kim YJ, Choi JY, Park HK, Park YH, et al. Impact of pressure load caused by right ventricular outflow tract obstruction on right ventricular volume overload in patients with repaired tetralogy of Fallot. J Thorac Cardiovasc Surg 2012;143:1299-304.

11. Helbing WA, de Roos A. Clinical applications of cardiac magnetic resonance imaging after repair of tetralogy of Fallot. Pediatr Cardiol 2000;21:70-9.

12. Helbing WA, Niezen RA, Le Cessie S, van der Geest RJ, Ottenkamp $\mathrm{J}$, de Roos A. Right ventricular diastolic function in children with pulmonary regurgitation after repair of tetralogy of Fallot: volumetric evaluation by magnetic resonance velocity mapping. $\mathrm{J}$ Am Coll Cardiol 1996;28:1827-35.

13. Rebergen SA, Chin JG, Ottenkamp J, van der Wall EE, de Roos A. Pulmonary regurgitation in the late postoperative follow-up of tetralogy of Fallot. Volumetric quantitation by nuclear magnetic resonance velocity mapping. Circulation 1993;88(5 Pt 1):2257-66.

14. Geva T. Indications and timing of pulmonary valve replacement after tetralogy of Fallot repair. Semin Thorac Cardiovasc Surg Pediatr Card Surg Annu 2006:11-22.

15. Geva T. Repaired tetralogy of Fallot: the roles of cardiovascular magnetic resonance in evaluating pathophysiology and for pulmonary valve replacement decision support. J Cardiovasc Magn Reson 2011;13:9.

16. Nollert G, Fischlein T, Bouterwek S, Bohmer C, Klinner W, Reichart B. Long-term survival in patients with repair of tetralogy of Fallot: 36-year follow-up of 490 survivors of the first year after surgical repair. J Am Coll Cardiol 1997;30:1374-83.

17. Murphy JG, Gersh BJ, Mair DD, Fuster V, McGoon MD, Ilstrup DM, et al. Long-term outcome in patients undergoing surgical repair of tetralogy of Fallot. N Engl J Med 1993;329:593-9.

18. Yetman AT, Lee KJ, Hamilton R, Morrow WR, McCrindle BW. Exercise capacity after repair of Tetralogy of Fallot in infancy. Am J Cardiol 2001;87:1021-3.

19. Ilbawi MN, Idriss FS, DeLeon SY, Muster AJ, Gidding SS, Berry TE, et al. Factors that exaggerate the deleterious effects of pulmonary insufficiency on the right ventricle after tetralogy repair. Surgical implications. J Thorac Cardiovasc Surg 1987;93:36-44.

20. Mulla N, Simpson P, Sullivan NM, Paridon SM. Determinants of aerobic capacity during exercise following complete repair of tetralogy of Fallot with a transannular patch. Pediatr Cardiol 1997;18:350-6.

21. Davlouros PA, Kilner PJ, Hornung TS, Li W, Francis JM, Moon JC, et al. Right ventricular function in adults with repaired tetralogy of Fallot assessed with cardiovascular magnetic resonance imaging: detrimental role of right ventricular outflow aneurysms or akinesia and adverse right-to-left ventricular interaction. J Am Coll Cardiol 2002;40:2044-52.

22. Karl TR, Sano S, Pornviliwan S, Mee RB. Tetralogy of Fallot: favorable outcome of nonneonatal transatrial, transpulmonary repair. Ann Thorac Surg 1992;54:903-7.

23. Sung SC, Kim S, Woo JS, Lee YS. Pulmonic valve annular enlargement with valve repair in tetralogy of Fallot. Ann Thorac Surg 2003;75:303-5. 
24. Kogon B, Plattner C, Kirshbom P, Kanter K, Leong T, Lyle T, et al. Risk factors for early pulmonary valve replacement after valve disruption in congenital pulmonary stenosis and tetralogy of Fallot. J Thorac Cardiovasc Surg 2009;138:103-8.

25. Munkhammar P, Cullen S, Jogi P, de Leval M, Elliott M, Norgard $\mathrm{G}$. Early age at repair prevents restrictive right ventricular (RV) physiology after surgery for tetralogy of Fallot (TOF): diastolic RV function after TOF repair in infancy. J Am Coll Cardiol 1998; 32:1083-7.

26. Lu JC, Cotts TB, Agarwal PP, Attili AK, Dorfman AL. Relation of right ventricular dilation, age of repair, and restrictive right ventricular physiology with patient-reported quality of life in adolescents and adults with repaired tetralogy of fallot. Am J Cardiol 2010;106:1798-802.

27. Cullen S, Shore D, Redington A. Characterization of right ventricular diastolic performance after complete repair of tetralogy of Fallot. Restrictive physiology predicts slow postoperative recovery. Circulation 1995;91:1782-9.

28. Gatzoulis MA, Clark AL, Cullen S, Newman CG, Redington AN. Right ventricular diastolic function 15 to 35 years after repair of tetralogy of Fallot. Restrictive physiology predicts superior exercise performance. Circulation 1995;91:1775-81.

29. Sachdev MS, Bhagyavathy A, Varghese R, Coelho R, Kumar RS. Right ventricular diastolic function after repair of tetralogy of Fallot. Pediatr Cardiol 2006;27:250-5.

30. Eroglu AG, Sarioglu A, Sarioglu T. Right ventricular diastolic function after repair of tetralogy of Fallot: its relationship to the insertion of a 'transannular' patch. Cardiol Young 1999;9:384-91.

31. Redington AN. Determinants and assessment of pulmonary regurgitation in tetralogy of Fallot: practice and pitfalls. Cardiol Clin 2006;24:631-9.

32. Eyskens B, Reybrouck T, Bogaert J, Dymarkowsky S, Daenen W, Dumoulin $\mathrm{M}$, et al. Homograft insertion for pulmonary regurgitation after repair of tetralogy of fallot improves cardiorespiratory exercise performance. Am J Cardiol 2000;85:221-5.

33. Warner KG, O’Brien PK, Rhodes J, Kaur A, Robinson DA, Payne DD. Expanding the indications for pulmonary valve replacement after repair of tetralogy of fallot. Ann Thorac Surg 2003;76:106671.

34. Frigiola A, Tsang V, Bull C, Coats L, Khambadkone S, Derrick G, et al. Biventricular response after pulmonary valve replacement for right ventricular outflow tract dysfunction: is age a predictor of outcome? Circulation 2008;118(14 Suppl):S182-90.

35. Harrild DM, Berul CI, Cecchin F, Geva T, Gauvreau K, Pigula F, et al. Pulmonary valve replacement in tetralogy of Fallot: impact on survival and ventricular tachycardia. Circulation 2009;119:445-51.
36. Therrien J, Provost Y, Merchant N, Williams W, Colman J, Webb G. Optimal timing for pulmonary valve replacement in adults after tetralogy of Fallot repair. Am J Cardiol 2005;95:779-82.

37. Oosterhof T, van Straten A, Vliegen HW, Meijboom FJ, van Dijk AP, Spijkerboer AM, et al. Preoperative thresholds for pulmonary valve replacement in patients with corrected tetralogy of Fallot using cardiovascular magnetic resonance. Circulation 2007;116:545-51.

38. Buechel ER, Dave HH, Kellenberger CJ, Dodge-Khatami A, Pretre $\mathrm{R}$, Berger F, et al. Remodelling of the right ventricle after early pulmonary valve replacement in children with repaired tetralogy of Fallot: assessment by cardiovascular magnetic resonance. Eur Heart J 2005;26:2721-7.

39. Lee C, Kim YM, Lee CH, Kwak JG, Park CS, Song JY, et al. Outcomes of pulmonary valve replacement in 170 patients with chronic pulmonary regurgitation after relief of right ventricular outflow tract obstruction: implications for optimal timing of pulmonary valve replacement. J Am Coll Cardiol 2012;60:100514.

40. Geva T, Gauvreau K, Powell AJ, Cecchin F, Rhodes J, Geva J, et al. Randomized trial of pulmonary valve replacement with and without right ventricular remodeling surgery. Circulation 2010; 122(11 Suppl):S201-8.

41. Kirklin JW, Blackstone EH, Pacifico AD, Kirklin JK, Bargeron LM Jr. Risk factors for early and late failure after repair of tetralogy of Fallot, and their neutralization. Thorac Cardiovasc Surg 1984;32: 208-14.

42. Chaturvedi RR, Kilner PJ, White PA, Bishop A, Szwarc R, Redington AN. Increased airway pressure and simulated branch pulmonary artery stenosis increase pulmonary regurgitation after repair of tetralogy of Fallot. Real-time analysis with a conductance catheter technique. Circulation 1997;95:643-9.

43. Kuehne T, Saeed M, Gleason K, Turner D, Teitel D, Higgins CB, et al. Effects of pulmonary insufficiency on biventricular function in the developing heart of growing swine. Circulation 2003; 108:2007-13.

44. Gundry SR, Razzouk AJ, Boskind JF, Bansal R, Bailey LL. Fate of the pericardial monocusp pulmonary valve for right ventricular outflow tract reconstruction. Early function, late failure without obstruction. J Thorac Cardiovasc Surg 1994;107:908-12.

45. Lurz P, Muthurangu V, Schuler PK, Giardini A, Schievano S, Nordmeyer J, et al. Impact of reduction in right ventricular pressure and/or volume overload by percutaneous pulmonary valve implantation on biventricular response to exercise: an exercise stress real-time CMR study. Eur Heart J 2012;33:2434-41. 